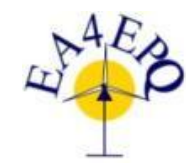

International Conference on Renewable Energies and Power Quality (ICREPQ'17) Malaga (Spain), $4^{\text {th }}$ to $6^{\text {th }}$ April, 2017

Renewable Energy and Pourer Qualiuy . Fournal (RE\&PQJ)

ISSN 2172-038 X, No.15 April 2017

\title{
Design and study of a Flat Plate Oscillating Heat Pipe. Flow Pattern analysis and Heat Transfer Performance
}

\author{
Authors: Fraga De Cal B. ${ }^{1}$, Vishak JK. ${ }^{2}$ \\ ${ }^{1}$ Department of Industrial II Engineering \\ E.P.S., A Coruña University \\ Campus of Esteiro - 15403 Ferrol (Spain) \\ Phone/Fax number: +34 981337400, e-mail: p.fraga@udc.es \\ ${ }^{2}$ Queen Mary University of London, School of Engineering and Material Science \\ Mile End Rd, London E1 4NS (United Kingdom) \\ Phone/Fax number: +919886300185, e-mail: v.jagadeeshkumar@se13.qmul.ac.uk
}

\begin{abstract}
Recent and constant demands for greater power densities and smaller sizes of electronic systems have stimulated the growth of new designs of different passive heat transfer methods such as heat pipes. Particularly, Oscillating Heat Pipes (OHPs) are relatively novel devices, capable of removing high heat rates over long and short distances with not much temperature drop. Its heat transfer mechanism relies on a self-oscillating motion of a two-phase flow of a working fluid circulating through meandering channels. This study concentrates on the design, building and assembling a test rig in order to analyse the flow pattern of deionised water through a 5 turns Flat Plate Oscillating Hat Pipe under different heat inputs, which was made in the School of Engineering and Materials Science of the Queen Mary University of London by two PhD students. The filling ratio of the water is $40 \%$. Furthermore an experimental study on the OHP thermal performance is carried out in order to examine the effects of different surface wet conditions: super hydrophilic, hydrophilic and cleaned brass. It is demonstrated the formation of liquid slugs and vapour plugs of the water along the channels. The experimental results showed that the hydrophilic surface tend to be more energy efficient. The heat transfer performance of the superhydrophilic and hydrophilic is higher than brass by $5-12 \%$ and $15-20 \%$ respectively
\end{abstract}

Keywords: Oscillating Heat Pipe, two-phase flow, liquid slugs, vapour plugs, heat transfer

\section{Introduction.}

Oscillating (or pulsating) heat pipes (OHP) are predicted to be a promising solution for the thermal management of compact cooling and have a wide variety of applications. 2013 Heat Transfer International Conference of American Society of Mechanical Engineers (ASME) [1] presented OHPs as an assuring novel technique for enhancing the energy efficiency throughout industry. It is a passive, innovative and efficient device introduced and registered in the nineties by Akachi [2].
OHPs consist of a serpentine channel of a tube of capillary dimensions, which has been partially filled with a working fluid as Figure 1 depicts. The heat input produces the evaporation and boiling of the working fluid, which increases the vapour pressure. This pushes the liquid slug towards the cooling part, where the bubbles begin condensing and the vapour pressure decreases. Thus, the liquid goes back to the heating section. The growth of the bubbles in both zones enables the self-excited oscillatory motion of liquid slugs and vapour plugs [3]. The process deals with a two-phase thermodynamic cycle and also entails a combination of different mechanisms: bubble nucleation, slug flow, condensation and pressure and temperature fluctuations. Heat pipes are non-equilibrium heat transfer devices and the phenomenon is complex to understand. It has still investigation shortage. For this reason much research on understanding the operating mechanism and the selfoscillating motion has been done until date.

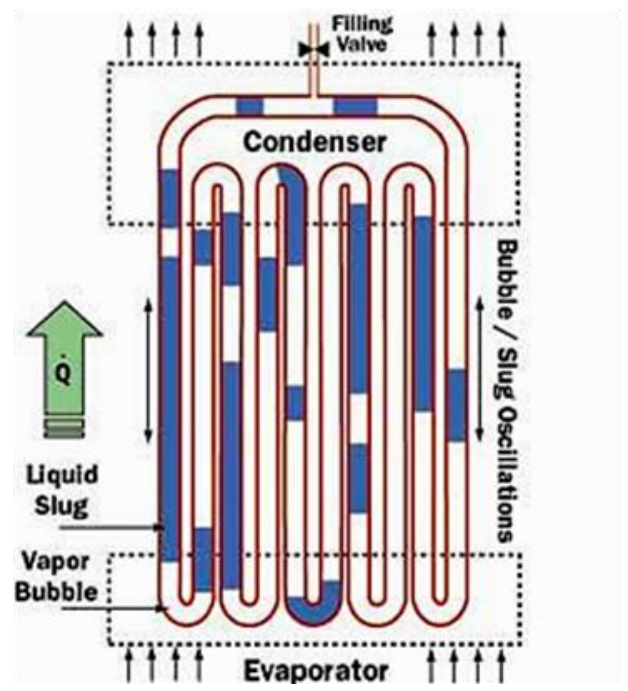

Figure 1. Schematic representation of closed-loop oscillating heat pipe (CLOHP) [4]. 
Previous experimental works have focused on the heat transfer mechanism and on the visualizations of flow patterns.

It's generally agreed, J. Qu et al. [5], H. Barua et al. [6], that the thermal performance and the flow regime of OHP depends on the effects of the working fluid, filling ratio (FR), power input, operating orientation and different geometries. The working fluid is commonly the most effective parameter to improve the thermal performance of heat pipes [7]

The difference between the power supplied in the evaporator zone and the heat released from the condenser part is usually less than 5\% [8]. All the authors stated the same way of measuring the performance of the OHP by estimating the overall thermal resistance of the device as a simple steady state system, given by equation below:

$$
R_{\text {OHP }}=\frac{\left(\mathrm{T}_{e}-T_{c}\right)}{Q_{\text {in }}}
$$

Where, $Q_{\text {in }}$ is the heat power input and, $\mathrm{T}_{\mathrm{e}}$ and $\mathrm{T}_{\mathrm{c}}$ are the mean temperature of the evaporator and condenser part.

The visualization of the fluid motion inside the heat pipe is strongly relevant for theoretical investigations on the fluid dynamics of the self-oscillating motion of the working fluid. X. Liu et al. [9] studied the flow patterns of a Flat Plate OHP of a solar collector unit. Ethanol is used under different filling ratios and a numerical model explains the bubble behaviour. It's concluded an average deviation of $11.3 \%$ between the experimental study and the numerical results regarding the size of the bubbles. Furthermore, they determined that the higher evaporator temperature, the better thermal performance.

The results of $\mathrm{T}$. Hao et al. [10] and related references argued the relationship between the surface of the pipes, its working fluid oscillation and heat transfer performance. These authors studied two copper FP-OHPs with four and six turns respectively and the flow pattern. It was observed dissimilar liquid-vapour interface depending on the number of the turns and surface wetting characteristics: superhydrophilic, hydrophilic, copper and hydrophobic. The authors concluded that the higher number of turns, higher thin film length and higher frequency oscillation. Hence, heat pipe with six turns showed better heat transfer performance. Also, a hydrophilic surface has a considerable positive effect on the slug motion and heat transfer performance in comparison with copper pipes. However, unlike OHP with four turns, the superhydrophilic surface presented higher thermal performance for six turns OHP and the dry out of the evaporator occurs at some heat inputs

\section{Experimental set up.}

\section{A. Test rig assembly}

It is designed and built an experimental test rig consisting of three main parts: a five-turn OHP, a heating system at the bottom of the heat pipe and a cooling system at the top of it, Figure 2 depicts this arrangement.
The OHP is made up of a brass plate (95\% cooper and $5 \%$ tin) $(140 \times 90 \times 10 \mathrm{~mm})$ where five meandering channels $(2 \times 2 \mathrm{~mm})$ were machined into the plate (Figure 3 ). Since the OHP operates in vertical position, the brass plate is covered by a polycarbonate (PC) sheet to prevent water from coming out and to observe the flow pattern through the channels. PC is chosen because of its convenient features including colourless and heat resistant up to around $130{ }^{\circ} \mathrm{C}$. Both brass plate and PC sheet have been hermetically sealed with a built and designed shape of silicone (Flexil-S, J24 RTV) mixed with a catalyst to avoid working fluid leakage (Figure 4). An own mould was fabricated by introducing the embossed drawing of the OHP on a numeric model milling machine. To fill the OHP with the working fluid, $1 \mathrm{~mm}$ diameter pipe and a valve were assembled on the top edge. Deionised water is used as working fluid.

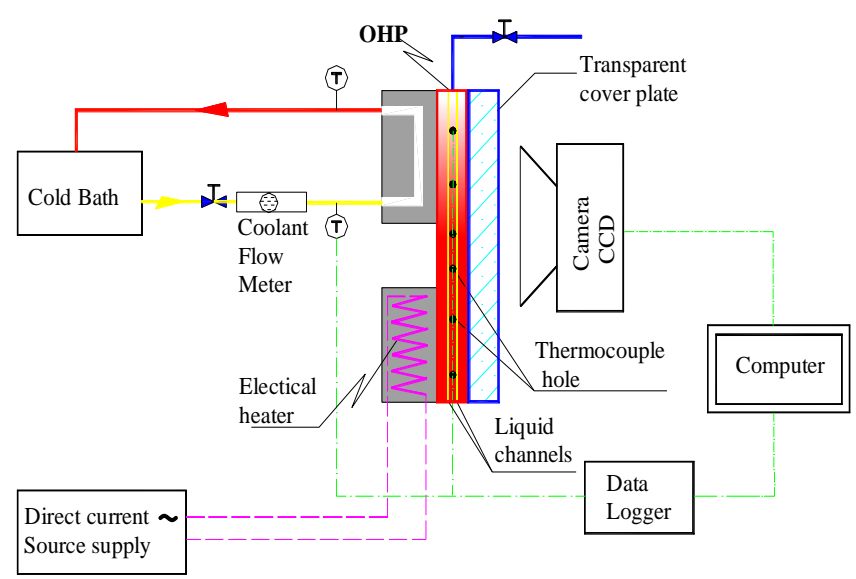

Figure 2. Schematic drawing of the experimental set up.
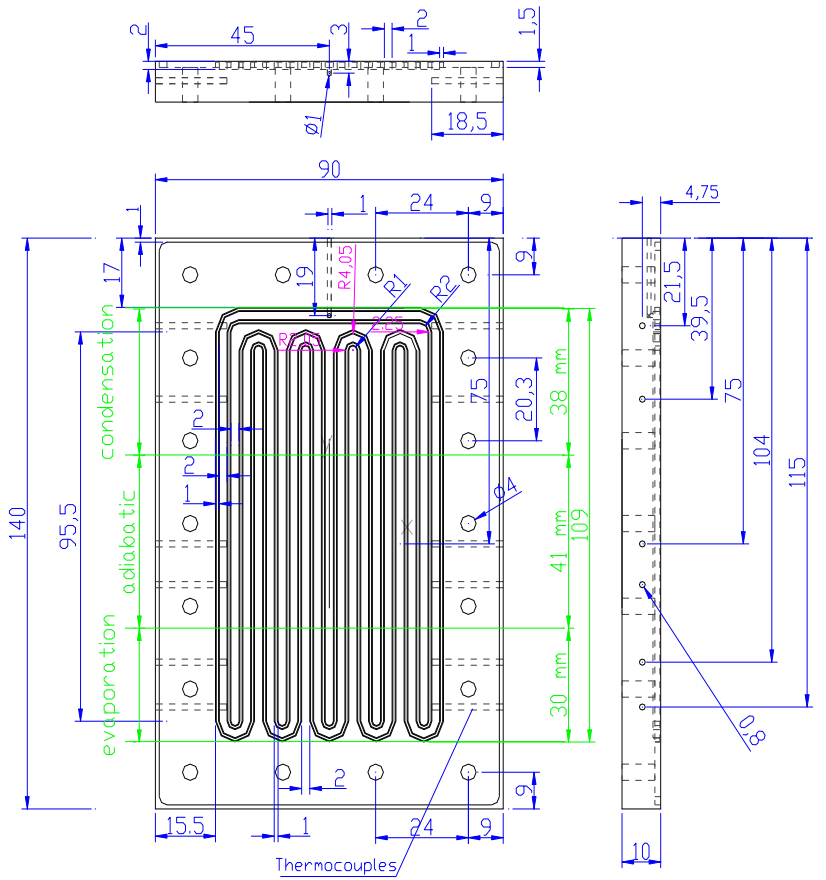

Figure 3. Oscillating Heat Pipe design.

The OHP's channels total length was $109 \mathrm{~mm}$, distributed in $30 \mathrm{~mm}$ evaporation section, $41 \mathrm{~mm}$ 
adiabatic section and $38 \mathrm{~mm}$ condensation section (Figure 3).

The evaporator zone of the OHP consists of a brass block attached in the rear lower side of the brass plate. A cartridge heater (RS, $400 \mathrm{~W}, 220 \mathrm{~V} \mathrm{ac}$ ) is inserted into this block to be connected to a power supply and then heating the water inside the channels. Cylindrical configuration instead of strip was selected due to the compactness of the cartridge heater and the small space available. The heat input is regulated by an autotransformer. The block is covered by a cork sheet in order to achieve minimum heat losses (Figure 4). Thus, the maximum heat transfer rate delivered by the cartridge heater is transferred to the evaporator zone. The maximum desired temperature in the meandering channels is $100^{\circ} \mathrm{C}$. Hence, the evaporator zone is designed to reach $115^{\circ} \mathrm{C}$ at the wall of the block next to the OHP in 15 minutes.

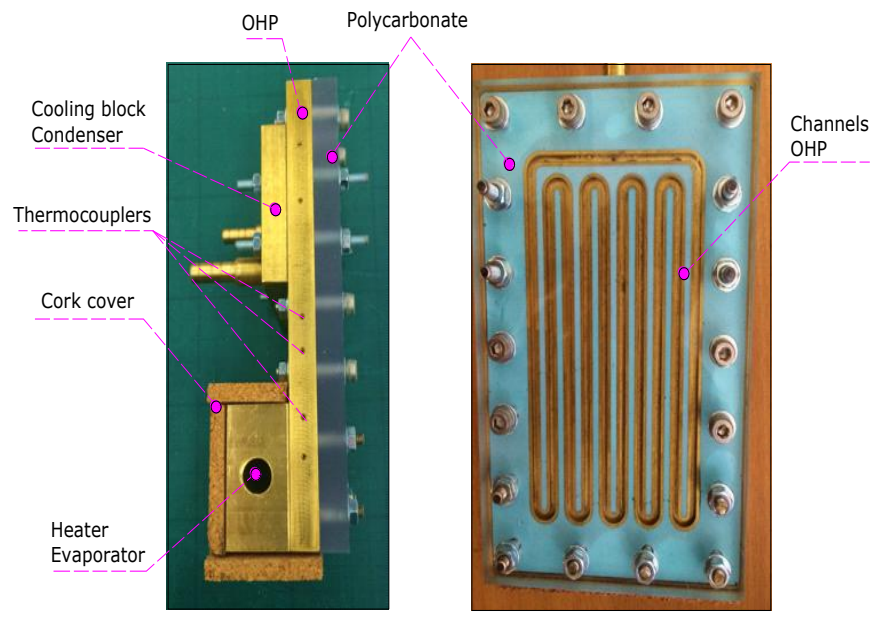

Figure 4. Assembly OHP

A cooling block is located at the top rear part of the OHP. This condenser part is cooled by water circulation at constant inlet temperature of $15{ }^{0} \mathrm{C}$ coming from a cold bath (Thermo Scientific, Phoenix II, $\pm 0.01 \mathrm{~K}$ ) and range flow rate of $200 \mathrm{ccm}$ to $3000 \mathrm{ccm}$. This flow rate is controlled by a flowmeter (Acrylic Flowmeter 200-3000 CCM, Instruments Direct, $\pm 3 \%$ ). The cold bath unit supplies a pressure pump to flow the water. PVC flexible tubes of $6 \mathrm{~mm}$ inner diameter are used for the connexions cooling circuit-cold bath-flowmeter (RS PVC 25 m long transparent tube).

As far as temperature measurement concerns, twelve perforations of $0.8 \mathrm{~mm}$ diameter were drilled in the sideways of brass plate and located just $2 \mathrm{~mm}$ beneath the channels with the purpose of placing thermocouples connecting to a data logger. Two more thermocouples are placed in the inlet and outlet of cooling block to measure water temperature. The thermocouples were calibrated for the range maximum of $\pm 0.1{ }^{\circ} \mathrm{C}$. For this study it is assumed an ambient temperature of $20^{\circ} \mathrm{C}$.

A two-valve valve is placed on the copper tube at the top of our OHP as can be seen in Figure 5. A vacuum pump is connected to this valve aiming to fill the channels with the working fluid without increasing the pressure. The working fluid was introduced by a syringe with the wanted filling ratio.

\section{B. Preparation of different surfaces.}

Before running the experiment, three surface wetting characteristics were prepared: the brass surface of the OHP was prepared to be cleaned brass, hydrophilic and superhydrophilic.

Firstly, the cleaned brass was achieved by washing the plate with sulphuric acid and deionised water. Then, in order to obtain a hydrophilic surface, a $\mathrm{CuO}$ coat layer was prepared. The brass plate was immersed in a solution of $2 \mathrm{~mol} / \mathrm{L} \mathrm{KOH}$ and $0.07 \mathrm{~mol} / \mathrm{L} \mathrm{K}_{2} \mathrm{~S}_{2} \mathrm{O}_{8}$ at $80^{\circ} \mathrm{C}$ for 30 min. Thus, the coat layer was created on the surface and the plate was dried at $120{ }^{\circ} \mathrm{C}$ for $45 \mathrm{~min}$. Finally with the purpose of creating a hydrophilic surface, previous $\mathrm{CuO}$ layer was submerged in a diluted $\mathrm{H}_{2} \mathrm{SO}_{4}$ bath. Afterwards, the OHP base was introduced in a 0.0020 $\mathrm{mol} / \mathrm{L}$ solution of $\mathrm{n}$-octadecyl mercaptan and in ethanol for $30 \mathrm{~min}$ at $70{ }^{\circ} \mathrm{C}$ [11]

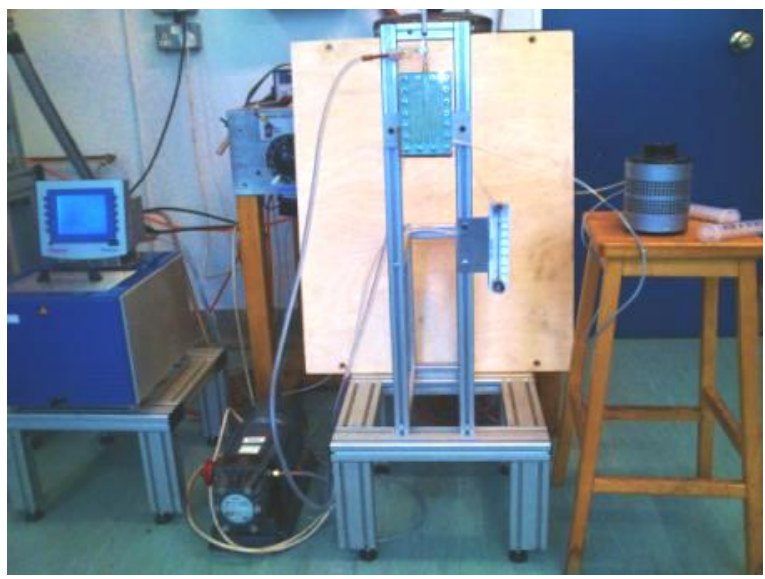

Figure 5. Test-rig configuration

\section{Results}

\section{A. Flow Pattern}

In total, 10 experimental runs at two different flow rates were performed with five different heat inputs: $400 \mathrm{~W}$, $200 \mathrm{~W}, 100 \mathrm{~W}, 50 \mathrm{~W}$ and $25 \mathrm{~W}$. The first set was run for a flow rate equals $200 \mathrm{ccm}$, which means laminar flow, and the other set for a flow rate equal to $1000 \mathrm{ccm}$. The filling ratio was $30 \%$ and the angle orientation was $90^{\circ} \mathrm{C}$, vertical position and bottom heat mode.

As the heat input increased, the working fluid required a period of $15 \mathrm{~min}$ to get a new stable state. The system was considered to be in a stable condition when the temperature between the thermocouples was lower than $0.2^{\circ} \mathrm{C}$.

First of all, it was observed the desirable effect: liquid slugs of water, as it is apparent from figure below. Hence, the design meets the requirements for the heat pipe operation. This phenomenon is because the surface tension forces are larger than gravitational forces.

The analysis and visualization indicate that by increasing the heat input from $25 \mathrm{~W}$ to $400 \mathrm{~W}$, the frequency of the bubbles motion increases also, but the flow pattern is 
essentially similar. A more powerful camera might appreciate this parameter change.

When the subcooled liquid reached the adequate temperature or in other words, when the wall temperature is higher than the saturated temperature (nucleate boiling), the regular flow pattern started with the relative quick growth of small bubbles in the evaporator zone. The velocity of bubbles growth depended on the heat input.

Due to convection and the consequent pressure increment, these small bubbles were dispersed until they coalescence and became vapour plugs which bring up the liquids slugs to the condenser, (Photo 1). This flow occurs at distinctly high velocity after ten seconds as maximum. The reason of these effects is fundamentally that when the water in the groove is heated and expands, its density is reduced and becomes more buoyant compared with the cooler water in the upper part.

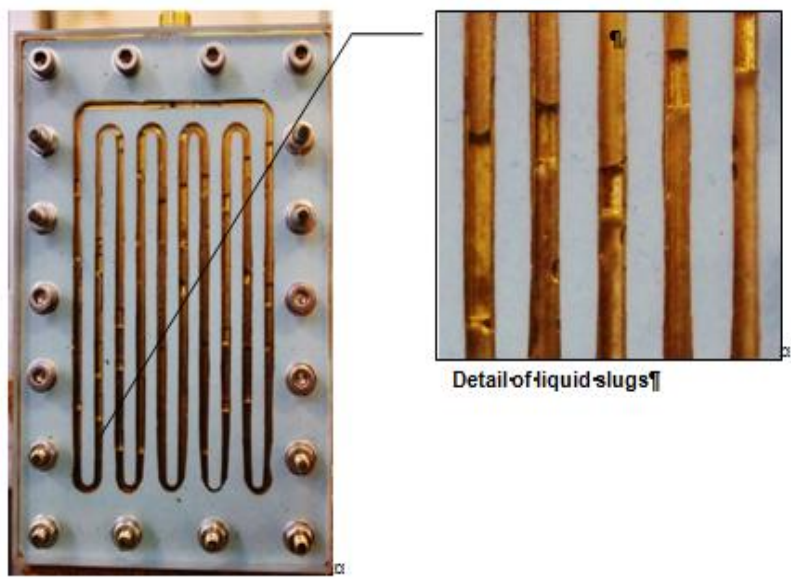

Photo 1. Expansion and contraction of the vapour plug. Startup, evaporation section.

Because of inertia and gravity, the liquid slugs returned from the condensation to the evaporation zone and compressed the vapour plugs flowing up. It was also found that some small liquid droplets coming from the condenser emerged from the thin liquid film adjacent to the wall at high heat inputs. However, the dry out of the evaporator did not take place. Even though, it could occur for longer periods.

The previous phenomenon caused the bursting of some bubbles. Consequently and similarly to an elastic spring, the expansion and consequent contraction originated the oscillating movement expected:

Finally, since the flow was very unstable, it is difficult to assert a type of flow regime, but it can be said that it was a combination of slug flow along the condenser and the adiabatic part, and annular flow at the bottom of the device. Thus, forced convection boiling and nucleate boiling seem to coexist in the heat pipe

\section{B. Surface effect on thermal performance}

It's compared the thermal resistance, the evaporation heat transfer coefficient and the heat load of three wetting surface conditions on the thermal performance of an OHP was studied.

It is clear from the graphs below that as the heat input increases, the thermal resistance decreases for all the cases.

Figure 6 illustrates the thermal resistance of the OHP for the three different surfaces at different heat input. The hydrophilic and superhydrophilic surfaces showed a better heat transfer performance than cleaned brass. The thermal resistance for the super hydrophilic surface was $10-20 \%$ higher thermal resistance than the hydrophilic one.

As is shown by Figure 7, both evaporation heat transfer coefficients in the superhydrophilic and hydrophilic OHP were higher than those for the cleaned brass.

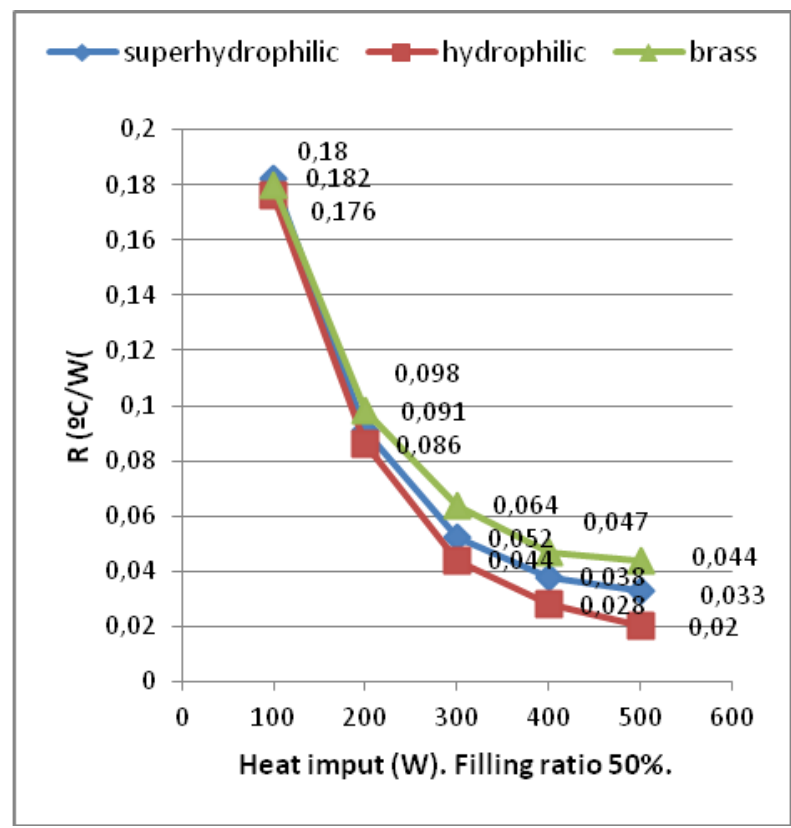

Figure 6. Thermal resistance of superhydrophilic, hydrophilic and cleaned brass at different heat inputs.

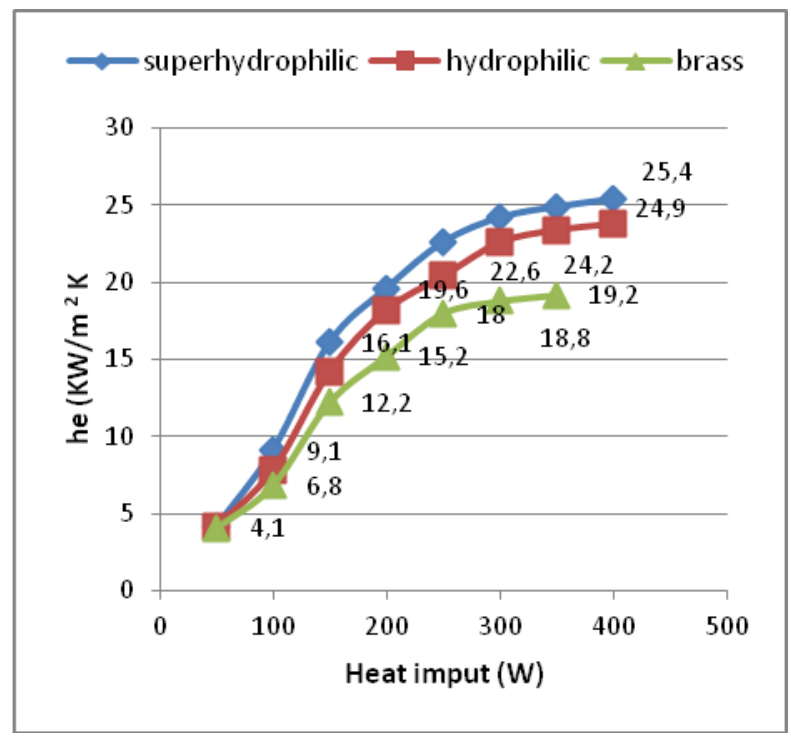

Figure 7. Evaporation Heat transfer coefficient of superhydrophilic, hydrophilic and cleaned brass at different heat inputs 
As can be seen from Figure 6 the thermal resistance were notably bigger in the hydrophobic OHP due to the less movement of the liquid slug, and the heat coefficient of the hydrophilic OHP was upper than that of the brass surface as shown in Figure 7 account of to the decrease of evaporation section temperatures.

\section{Filling Ratio effect on the thermal performance}

The heat load, the start-up temperature and start-up power were evaluated at filling ratios of $30 \%, 50 \%$ and $75 \%$. It's apparent from Figure 6 that there is a reduction in the heat transfer performance with the increment of the the filling ratio. The graph also shows that the hydrophilic surface presented the highest heat load in comparison with the superhydrophilic and cleaned brass.

Figure 9 and Figure 10 reveal that the hydrophilic surface displayed the lowest startup power and temperature while the brass showed the lowest ones. The startup temperature of the superhydrophilic, hydrophilic and brass $\mathrm{OHP}$ varied from 34 to $45^{\circ} \mathrm{C}, 33$ to $49^{\circ} \mathrm{C}$, and 30 to $40^{\circ} \mathrm{C}$ respectively.

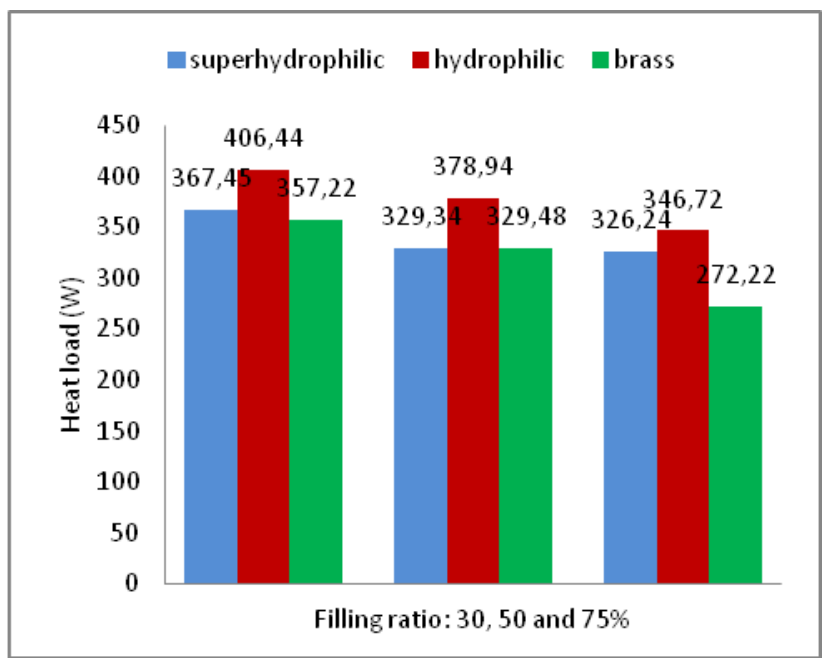

Figure 8. Heat load of the OHP.

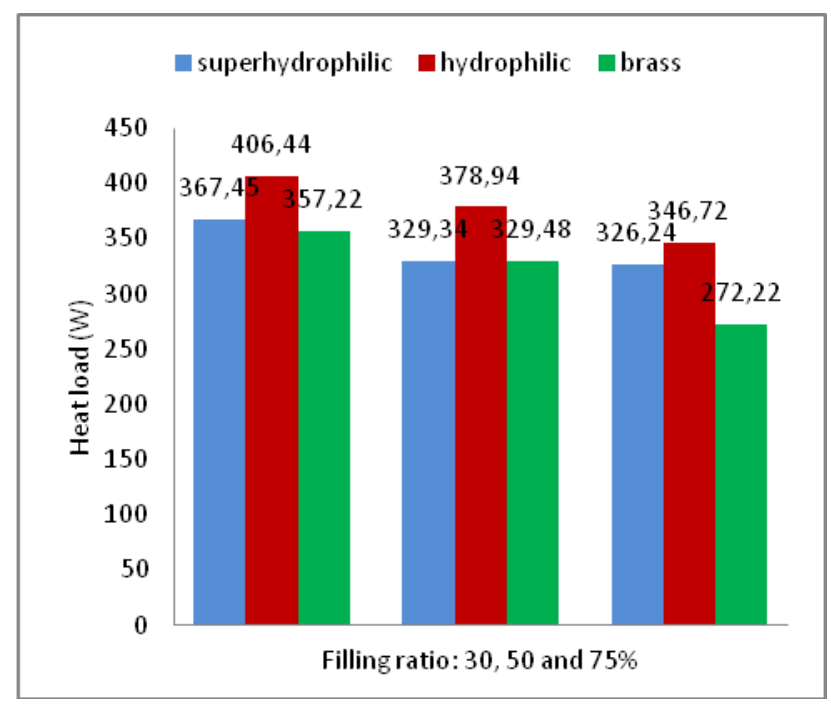

Figure 9. Startup power, superhydrophilic, hydrophilic and brass surface

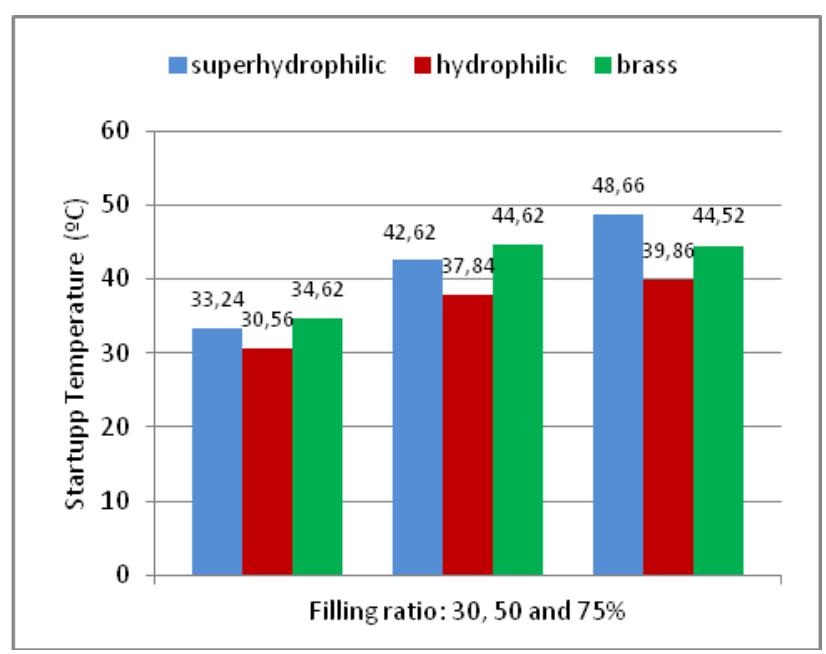

Figure 10. Startup Temperature, superhydrophilic, hydrophilic and brass.

\section{Conclusions}

From the test rig built and the research carried out the following points can be concluded:

- The design of the heat pipe meets the original conditions for its operation. Surface tension was higher than gravity forces.

- There must be sufficient liquid in the system to transfer sensible heat and create the flow featuring with vapour plugs and liquid slug

- The temperature difference between the liquid slug and the capillary wall was high enough at $25 \mathrm{~W}$ to cause the bubble growth

- Collapse and breakage of bubbles, coupled with nucleate boiling took place inside the engraved channels. All this phenomenons combined in the same system means a relatively complicate and unstable behaviour.

From the heat transfer performance, it's conclude the following,

- As expected, super hydrophilic and hydrophilic surface showed a higher thermal performance than cleaned brass. OHP.

- The hydrophilic surface reflected the lowest thermal resistance of the wet conditions analysed.

- The heat transfer coefficients in the superhydrophilic and hydrophilic OHP were approximately $20 \% \%$ higher than in brass OHP.

- In comparison with cleaned brass, the heat input required in the hydrophilic surface fall by 22 to $28 \%$ for the working fluid filling ratio of 30,50 and $75 \%$. A hydrophilic surface results in a better energy efficiency device.

- The startup temperature at which the self-oscillating process of OHP begins of the hydrophilic in contrast with 
clean brass surface OHP is reduced about 12 to $16 \%$ according filling ratio of 30,50 and $75 \%$

- The heat transfer performance is reduced as the filling ratio is increased.

Despite the remarkable attempts in the last two decades, further investigation in OHPs is fundamentally needed. Refrigeration devices and heat sinks are usually substantially large and locations are limited for them. Hence, reducing the volume and weight of innovative cooling systems would lead to more efficient compact electronics and consequently, to energy and monetary savings.

In comparison with conventional heat pipes, oscillating heat pipes show prominent advantages such as: simple structure (no necessity of manufacturing complex and expensive wick structures), low cost and low weight.

\section{Acknowledgements}

This work would not have been possible without the support and guidance of my supervisor, Dr. Hua Sheng Wang. It is essential to highlight the professionalism of the manufacture technician, Mr Vince Ford. Thanks to the research team of Nanoforce Lab for their instruments and advises when it comes to make silicone moulds.

\section{References}

[1] S. Khandekar, P. Chareoensawan, Manfred Groll, P. Terdtoon, «Closed Loop pulsating heat pipes,» Applied Thermal Engineering, vol. 23, pp. 2021-2033, 2003.

[2] H.Akachi, «Structure of a heat pipe». United States Patente 4921041, 1 May 1990.

[3] A. Faghri, «Review and advances in heat pipe science and technology,» Journal of Heat Transfer, vol. 134, pp. 1-17, 2012.

[4] D. a. P.A.Kew, Heat Pipes. Theory, Design and Applications, Great Britain: Elsevier, 2006.

[5] J.Qu, Q.Wang, «Experimental study on the thermal performance of vertical closed-loop oscillating heat pipes and correlation modelling,» Applied Energy, vol. 112, pp. 1154-1160, 2013.

[6] H. Barua, M. ALi, Md. Nuruzzaman, M. Quamrul, CM. Feroz, «Effect of filling ratio on heat transfer characteristics and performance of a closed loop pulsating heat pipe,» 5th BSME International Conference on Thermal Engineering, vol. 56, pp. 88-95, 2013.

[7] U. W. H.B. Jagtab, «Review on thermal performance of oscillating heat pipe with different working fluids,» International Journal of Applied Engineering Research, vol. 10, nº 4, pp. 9335-9353, 2015.

[8] K.H. Chien, Y.T. Lin, Y.R. Chen, K.S. Yang, C.C. Wang, «A novel design of pulsating heat pipe with fewer turns applicable to all orientations,» International Journal of Heat Transfer, vol. 55, pp. 5722-5728, 2012.

[9] X. Liu, Y.Chen, «Fluid flow and heat transfer in flat-plate oscillating heat pipe.,» Energy and buildings, vol. 75, pp.
29-42, 2014.

[10] T. Hao, X. Ma, Z. Lan, N. Li, Y. Zhao, H. Ma, «Effects of hydrophilic surface on heat transfer performance and oscillating motion for an oscillating heat pipe,» International Journal of Heat Transfer, vol. 72, pp. 50-65, 2014.

[11] S. S. Rapolu P, «Characterization of wettability effects on pressure drop of two-phase flow in microchannels.,» Experiments in Fluids, $\mathrm{n}^{\circ}$ 51, pp. 1101-1108, 2011. 